Martín Fernández, Diego.

Profesor Escuela de Arte de Algeciras (Cádiz). Investigador, Universidad de Barcelona, Facultad de Bellas Artes, Departamento de Diseño e Imagen.

Martín Segura, José Aureliano.

Profesor del Departamento de Organización de Empresas de la Universidad de Granada. Investigador del Grupo Innovación, Sostenibilidad y Desarrollo Empresarial (ISDE).

\title{
La importancia de la reflexión antes del disparo fotográfico. Un análisis estadístico de las preferencias de los usuarios.
}

\section{The Importance Of Reflection Before Taking A Photograph. A Statistical Analysis Of User Preferences.}

\author{
TIPO DE TRABAJO:
}

Comunicación.

PALABRAS CLAVE:

Fotografía; Educación Artística; Método de Enseñanza; Tecnología de la Educación; Disciplina.

KEY WORDS:

Photography, Art Education, Teaching Methods, Technology Education, Discipline.

RESUMEN

El refinamiento de las cámaras digitales y la facilidad con la que muchos fotógrafos, sobre todo los más jóvenes, logran captar una imagen mediante pasos sencillos e intuitivos sin necesidad de contar con conocimientos técnicos profundos, ha provocado una considerable preocupación entre los docentes de la especialidad fotográfica.

Este estudio pretende conocer, desde una revisión bibliográfica e indagación sociológico estadística sobre el estado de la fotografía vinculada al arte, si la actitud generalizadamente mecánica que parece haberse extendido entre un porcentaje significativo de aficionados a la fotografía afecta también a los profesionales o si, por el contrario, prestan atención a la expresión fotográfica y su intención más allá del disparo.

De ahí que la primera cuestión consista en conocer en qué medida ha repercutido el uso de esta tecnología cada vez más intuitiva en los procesos de trabajo de los profesionales y si ocurre porque el código fotográfico se encuentra tan asumido que se ignoran todas las decisiones que toma un fotógrafo antes de realizar una fotografía.

El segundo planteamiento pretende aclarar si ante la revolución que aporta el sistema digital resulta necesario posicionar de nuevo a la fotografía bajo un sistema de trabajo controlado e intencionado, lo que haría necesario redefinir las funciones del fotógrafo.

Se podrían así comenzar a concretar la tercera y cuarta duda: si existe una idiosincrasia de la fotografía (la esencia) y si se puede proponer un 'buen hacer' fotográfico sobre el panorama actual digital. 


\section{ABSTRACT}

The refinement of digital cameras and the ease with which many photographers, especially younger ones, manage to capture an image by means of simple and intuitive steps, without the need for detailed technical knowledge, has caused considerable concern amongst photography teachers.

This study aims to discover, from a bibliographic revision and statistical sociological investigation into the state of photography linked to art, if the widespread mechanical attitude that seems to have taken hold amongst a significant percentage of photography enthusiasts also affects the professionals or if, on the other hand, they pay attention to photographic expression and its intention beyond simply pressing the button.

Therefore, the first question consists of establishing to what extent the work processes of the professionals have been affected by the use of this ever more intuitive technology, and asking if this occurs because the photographic code is so assimilated that all the decisions a photographer makes before taking a photograph are disregarded.

In the face of the revolution brought about by the digital system, the second approach aims to clarify if there is once again a need for a controlled and deliberate photographic process, which would make it necessary to redefine the functions of the photograph.

Here we can begin to specify the third and fourth doubts: if there exists an idiosyncrasy of photography (the essence) and if it is possible to propose a photographic 'good practice' in the current digital panorama.

\section{CONTENIDO.}

\section{INTRODUCCIÓN.}

Los avances fotográficos del desarrollo tecnológico aportan más ventajas que inconvenientes, lo que provoca que los nuevos profesionales sobrevaloren la posproducción y, del mismo modo, que parte de los que se han formado en un sistema fotoquímico se resistan al sistema digital.

La evolución siempre busca mejorar lo presente para hacerlo más cómodo porque, como explicó Ute Daniel (2005: 390), "el desarrollo es un cambio irreversible en el tiempo, que garantiza la continuidad de un mundo mutable".

Pero dos de esas supuestas mejoras del sistema digital, con un proceso de revisado fácil e instantáneo, recaen en que la fotografía queda más expuesta al accidente o el ensayo-error, y en obviar todos los requisitos técnicos al creer que cualquier cosa se puede solucionar después.

El gran problema de esta percepción, no necesariamente negativa aunque mayoritariamente compartida entre quienes trabajaron o se formaron con el proceso anterior, son sus consecuencias.

Sin embargo, el conformismo no es un valor que los grandes fotógrafos hayan llevado por bandera. Al mirar las experiencias pasadas que se producen a modo de esquemas para continuar en el presente, se comprueba que quienes supieron aprovechar las posibilidades de la máquina de manera práctica -los funcionarios ${ }^{1}$, fueron los que llegaron a entenderla como un medio para favorecer el modo de vida. Si se parte de la idiosincrasia del medio fotográfico, una imagen que respeta la realidad es la que ofrece un positivo totalmente acabado antes del disparo.

Por tanto, no se pretende rechazar la intervención de la imagen después de tomarla, pero sí recalcar el destino de la fotografía y recordar que cuanta más información se obtenga en la fase inicial, más opciones habrá en la edición. Cuando una toma se realiza siguiendo un método de trabajo, con dominio de la técnica y consciencia de la importancia de previsualizar la fotografía, se ahorra tiempo en la postproducción y se logra una la calidad final de la imagen superior.

\footnotetext{
1 Vilem Flusser llama "funcionarios" (Flusser, 1990:28) a quienes controlan un juego (el de fotografiar) y están al acecho de las infinitas combinaciones de símbolos (de espacio y tiempo) a través del aparato, con las que crear nuevos significados.

La explicación a esto es la de cualquier aparato relacionado con la cultura: los objetos que producen cultura, como es el caso de la cámara fotográfica (las fotografías), no tienen un fin consumible sino que son un recurso o medio de apoyo para la información. Es decir, para consumir un objeto, primero hay que informarlo (modificarlo), con trabajo, que en el caso de la fotografía incluye informar (cambiar) no el mundo sino su significado. Lo que hace pensar que el fotógrafo no trabaja, sino que produce, procesa y abastece de símbolos, así como un compositor o un ilustrador.
} 
Por eso, el objetivo más importante de este trabajo reside en dilucidar si una de las consecuencias de la excesiva seguridad apuntada, por la creencia de que la fotografía se puede corregir después de la toma, provoca que los profesionales olviden la importancia de la reflexión y de la previsualización -la clave del 'buen hacer fotográfico'-, para fotografiar sin una idea previa, de manera espontánea y con la intención de crear un efectismo en la postproducción.

\section{DESARROLLO}

Por todo esto, la idea principal del trabajo no es anticiparse a la realidad (Laguillo, 1995), sino conocerla profundizando en las teorías y conceptos afines al problema descrito. Así, se buscó una hipótesis objetiva y no solo una sospecha propiciada por la experiencia del autor, y se sumó el trabajo para intentar entender cómo los fotógrafos se relacionan con el equipo y con el mundo desde una revisión bibliográfica y la indagación sociológica sobre el estado de la fotografía vinculada al arte, la tecnología y la profesión en este momento:

- Observar las aptitudes, sentimientos y valores que desarrollan los profesionales, aficionados competentes y estudiantes de la especialidad respecto al sistema fotográfico, y hacerlo recorriendo desde los últimos años del sistema argéntico y hasta el asentamiento de la tecnología digital.

- Localizar los nuevos comportamientos aprehendidos en la fotografía, los derivados del uso fotográfico tradicional (que se han mantenido iguales o los que han adquirido una nueva forma), para precisar cómo infieren en los resultados del quehacer fotográfico.

- Comprobar si la transformación que ha sufrido el oficio es fruto del desarrollo tecnológico actual y, consecuentemente, de una mentalidad nueva generalizada entre la población de casi todas las generaciones.

- Revisar qué debe cubrir el 'buen hacer' fotográfico para obtener la fotografía adecuada, y que ese 'buen hacer' sea aplicable a los dos sistemas que aún conviven.

- Buscar qué le ha interesado a los fotógrafos con mentalidad digital de los métodos tradicionales para argumentar de manera objetiva qué se pretende conseguir de la cámara.

Para indagar en lo anterior, se diseñó un el cuestionario 'El valor de una fotografía', que se situó en una plataforma on line dirigida por grupos a profesionales del sector, incluidos docentes de la especialidad, alumnos de los últimos cursos en centros oficiales o no oficiales que enseñan la especialidad de fotografía y a aficionados comprometidos. De manera paralela, se conoció la población objetivo porque se contactó con fotógrafos profesionales, tiendas especializadas, asociaciones, agrupaciones o plataformas que se ofrecieron a responder y exponerla también en sus redes sociales. Se avanzó además con los jefes de los departamentos de Fotografía de las Escuelas de Arte de toda España (públicas), centros privados y facultades de Bellas Artes que imparten la especialidad fotográfica. En este caso, con la intención de que facilitaran dicho enlace a sus alumnado de cursos avanzados (en su mayoría entre 20-25 alumnos) y al profesorado de fotografía del centro (entre 4 y 5) (Santos, 1999:89).

Las variables utilizadas fueron aquellas en las que se tuvieron en cuenta aspectos importantes dentro de la práctica fotográfica, como la transformación de la profesión, datos sociodemográficos y situación laboral como sexo, nivel de estudios alcanzados, pertenencia a asociaciones fotográficas, lugar de residencia, grado de uso del laboratorio o la importancia otorgada a valores anteriores y posteriores a la toma fotográfica o de elementos asociados a la fotografía.

Finalmente, todos los resultados del cuestionario se exportaron al programa de análisis estadístico SPSS 20, a través del cual se realizó el correspondiente análisis descriptivo y predictivo, mediante las técnicas estadísticas adecuadas (Pérez, 2009: 43-44). Para el análisis descriptivo, se usaron tablas de frecuencias, medidas de posición central y gráficas. Para el análisis predictivo se usó un modelo multivariante de datos de análisis de la varianza y covarianza múltiple MONCOVA.

Las variables se dividieron en independientes y dependientes. Las independientes, también denominadas variables predictoras, fueron aquellas que entendíamos que definían mejor el "buen hacer fotográfico". Para ello se tuvieron en cuenta los años dedicados a la fotografía, los estudios relacionados con la fotografía y la formación relacionada con la fotografía. Del análisis descriptivo de las respuestas de estas variables, se deduce que a pesar de que la máquina fotográfica es cada vez más intuitiva y sencilla, se percibe un alto porcentaje de usuarios formados oficialmente en la especialidad o en estudios relacionados con la imagen. Además, el interés por seguir formándose lo evidencian más del 82 \% de los encuestados. Por lo tanto, el número fotógrafos autodidactas es menor y la importancia del docente guía se incrementa. 
Atendiendo al vínculo entre aquellos usuarios que han vivido la fase de cambio entre sistemas, que han recibido formación relacionada con fotografía y que continúan formándose, se observa especialmente que quienes más claramente han vivido la fase de tránsito de un sistema a otro, dedicados profesionalmente a la fotografía, actualmente consideran igual de importantes la fase anterior y posterior al disparo. Manifiestan así una clara aceptación del sistema digital. Asimismo, rechazan el sistema fotoquímico y consideran lo digital de manera muy positiva porque marcan que "en su práctica fotográfica usan exclusivamente el sistema digital", que "usan habitualmente la cámara digital" y que tras la toma, "sí realizan tratamiento informático". Suelen apreciarlo como un proceso completamente distinto al analógico, con resultados que poco tienen que ver con el anterior. Además, marcan que comparando ambos sistemas "ni han mejorado, ni empeorado uno respecto al otro". Y que generalmente, en su actividad fotográfica "la fase anterior es igual de importante que el previo" o que "la anterior es más importante" (Ilustración V).

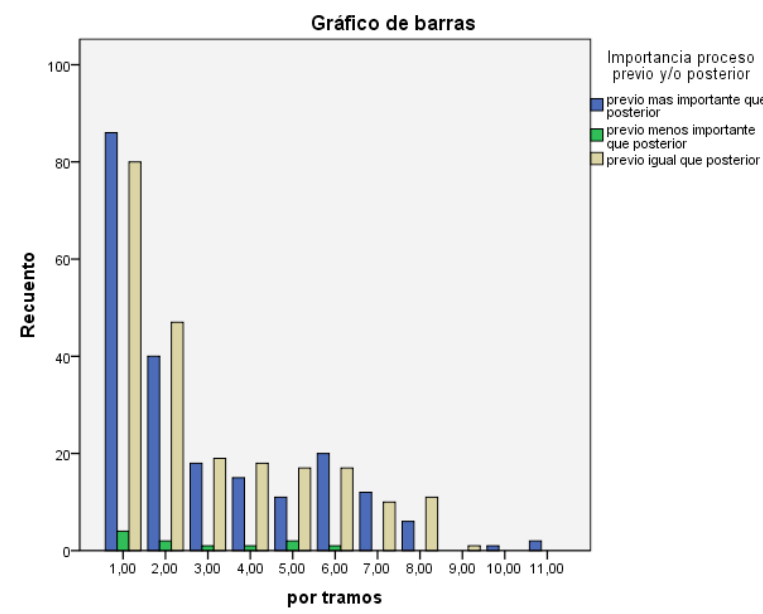

Sin embargo, los nativos digitales y los que tienen más experiencia, aceptan de manera favorable el nuevo sistema, pero sin perder de vista el proceso anterior y señalan que "en su práctica fotográfica usan más sistema digital que tradicional" (Ilustración VI). Esto puede deberse, en el caso de los veteranos, a que no han llegado a adaptarse. Entre los más jóvenes, el motivo responde a la falta de experiencia real (profesionalmente hablando) como para decantarse por un valor sobre otro, la dificultad para encontrar materiales 0 no disponer de medios, espacio o por falta de tiempo.

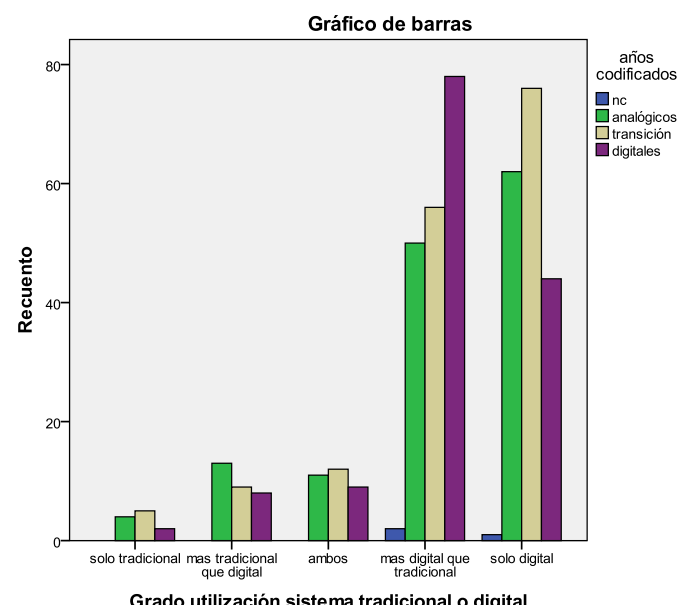

En lo referente a las variables dependientes, también denominadas variables respuesta o endógenas, partiendo de parámetros ya tratados por autores como Luis Castelo (2006), Stephen Shore (2009), P. R. Petruck (1979) o Vauclare, C. y R. Debeauvais (2014), se definieron las cinco que considerábamos que mejor definían el buen hacer fotográfico, cada una de las cuales se componía a su vez de un conjunto de características que mejor las identificaban. Estas fueron: importancia de los elementos de la fase previa y posterior a la toma fotográfica, uso de programas de edición de imágenes (Adobe Lightroom y Camera RAW) e importancia de la edición previa y 
posterior en el sistema digital. La primera variable de importancia de la fase previa, se resumió en dos factores, que se obtuvieron después de realizar la correspondiente reducción estadística de la dimensión. El primero agrupaba variables como control de iluminación, fidelidad en la representación de valores, escala tonal y texturas, preparar bien la toma antes del disparo y controlar bien el funcionamiento del aparato de forma manual. El segundo factor agrupaba la creatividad, composición y organización de los elementos plásticos del encuadre, deseo de control desde una visión personal y intención del fotógrafo. Para la fase posterior, se construyó un único factor, compuesto de variables como partir de un buen negativo, acabado y presentación final y destino final de la fotografía. Nuestro interés era obtener evidencias estadísticas significativas sobre ese grupo de variables que sintetizaban el buen hacer fotográfico', de las que habíamos considerado independientes, como la experiencia, los estudios y la formación, para así dar respuesta a las hipótesis planteadas. De esta forma habríamos captado y medido el sentir y tendencia de los profesionales de la fotografía en nuestro país.

Para intentar corroborar las anteriores hipótesis de trabajo de forma estadística se ha utilizado el modelo de análisis de la varianza y covarianza múltiple MANCOVA, que realiza estimaciones para comprobar, con un nivel de confianza del $95 \%$, si un grupo de variables independientes tienen alguna influencia estadísticamente significativa en el grupo de variables dependientes que definen el buen hacer fotográfico. Los análisis previos para comprobar la validez del modelo arrojaron un resultado positivo.

El análisis de las estimaciones de los parámetros (Tabla I) muestra que sus coeficientes presentan una significación aceptable, con pvalor bajo en muchas de las variables independientes y dependientes, lo que significa con una confianza del $95 \%$, que las variables independientes con un coeficiente de $p$-valor bajo, ejercen una influencia estadísticamente significativa en la variable dependiente, ya sea esta positiva o negativa. Por tanto, de las estimaciones obtenidas del análisis de la muestra se pueden inferir conclusiones de comportamiento para la totalidad de la población.

Tabla 1

\begin{tabular}{|c|c|c|c|c|c|c|c|c|c|c|}
\hline \multicolumn{11}{|c|}{ Estimaciones de los parámetros } \\
\hline \multirow{2}{*}{$\begin{array}{l}\text { Variable } \\
\text { dependiente }\end{array}$} & \multirow[t]{2}{*}{ Parámetro } & \multirow[t]{2}{*}{$B$} & \multirow[t]{2}{*}{ Error } & \multirow[t]{2}{*}{$\mathrm{t}$} & \multirow[t]{2}{*}{ Sig. } & \multicolumn{2}{|c|}{$\begin{array}{l}\text { Intervalo de } \\
\text { confianza 95\% }\end{array}$} & \multirow{2}{*}{$\begin{array}{l}\text { Eta al } \\
\text { cuadrado } \\
\text { parcial }\end{array}$} & \multirow{2}{*}{\begin{tabular}{|l|} 
Parámetro \\
de no \\
centralidad \\
Parámetro
\end{tabular}} & \multirow{2}{*}{$\begin{array}{l}\text { Potencia } \\
\text { observada }^{b}\end{array}$} \\
\hline & & & & & & $\begin{array}{l}\text { Límite } \\
\text { inferior } \\
\end{array}$ & \begin{tabular}{|l} 
Límite \\
superior
\end{tabular} & & & \\
\hline \multirow{6}{*}{$\begin{array}{l}\text { REGR factor } \\
1 \text { for } \\
\text { analysis } 5\end{array}$} & Intersección &,- 387 & ,246 & $-1,576$ & ,116 &,- 870 & ,096 &, 006 & 1,576 &, 350 \\
\hline & P17c & 046 &, 020 & 2,267 & 024 &, 006 & 085 & 011 & 2,267 & 619 \\
\hline & {$[\mathrm{P} 7 \mathrm{c}=0]$} &,- 004 & 445 &,- 009 & ,993 &,- 878 & 870 & ,000 & ,009 & 050 \\
\hline & {$[\mathrm{P} 7 \mathrm{c}=1]$} &,- 029 & 267 &,- 109 & ,914 &,- 554 &, 496 & 000 & 109 & 051 \\
\hline & {$[\mathrm{P} 10 \mathrm{c}=0]$} & ,159 & ,394 & ,403 & ,687 &,- 615 & 932 &, 000 & ,403 & 069 \\
\hline & [P10c=1] &, 422 & ,376 & 1,123 &, 262 &,- 317 & 1,161 & 003 & 1,123 & ,202 \\
\hline \multirow{6}{*}{$\begin{array}{l}\text { REGR factor } \\
2 \quad \text { for } \\
\text { analysis } 5\end{array}$} & Intersección & 056 & 251 & ,224 &, 822 &,- 436 & ,549 & ,000 & ,224 & 056 \\
\hline & P17c & ,021 & ,021 & 1,023 & ,307 &,- 019 & ,061 & ,002 & 1,023 & ,175 \\
\hline & {$[P 7 c=0]$} &,- 578 & ,454 & $-1,274$ & ,203 & $-1,469$ & ,314 & ,004 & 1,274 & ,246 \\
\hline & {$[P 7 c=1]$} &,- 226 & ,272 &,- 831 & ,407 &,- 761 &, 309 &, 002 & ,831 & ,132 \\
\hline & {$[\mathrm{P} 10 \mathrm{c}=0]$} & ,391 & ,401 & ,974 & ,331 &,- 398 & 1,180 & 002 & 974 & ,163 \\
\hline & [P10c=1] & ,527 & ,383 & 1,374 & ,170 &,- 227 & 1,280 & ,004 & 1,374 & ,278 \\
\hline \multirow{6}{*}{$\begin{array}{l}\text { REGR factor } \\
1 \quad \text { for } \\
\text { analysis } 6\end{array}$} & Intersección & $-2,97$ & ,201 & \begin{tabular}{|l}
$-14,82$ \\
\end{tabular} &, 000 & \begin{tabular}{|l|}
$-3,372$ \\
\end{tabular} & $-2,583$ & ,329 & 14,823 & 1,000 \\
\hline & P17c & ,033 & ,016 & 2,003 & ,046 & ,001 & ,065 & 009 & 2,003 &, 516 \\
\hline & {$[P 7 c=0]$} & 2,644 & ,364 & 7,269 & ,000 & 1,929 & 3,359 & ,105 & 7,269 & 1,000 \\
\hline & {$[\mathrm{P} 7 \mathrm{c}=1]$} & 2,710 & \begin{tabular}{|l|}
, 218 \\
\end{tabular} & \begin{tabular}{|l|}
12,412 \\
\end{tabular} &, 000 & 2,281 & 3,139 & ,256 & 12,412 & 1,000 \\
\hline & {$[\mathrm{P} 10 \mathrm{c}=0]$} & ,136 & ,322 &, 424 & ,672 &,- 496 & ,769 & ,000 &, 424 & ,071 \\
\hline & {$[\mathrm{P} 10 \mathrm{c}=1]$} & ,514 & ,307 & 1,671 &, 095 &,- 091 & 1,118 &, 006 & 1,671 & ,385 \\
\hline \multirow{6}{*}{ Lightroom } & Intersección & 1,736 & , 122 & 14,197 &, 000 & 1,495 & 1,976 & ,310 & 14,197 & 1,000 \\
\hline & P17c & ,018 & ,010 & 1,767 &, 078 &,- 002 &, 037 &, 007 & 1,767 & ,422 \\
\hline & {$[P 7 c=0]$} & $-1,05$ & ,221 & $-4,763$ &, 000 & $-1,489$ &,- 619 & ,048 & 4,763 & ,997 \\
\hline & {$[P 7 c=1]$} & $-1,08$ & ,133 & $-8,178$ &, 000 & $-1,348$ &,- 825 & ,130 & 8,178 & 1,000 \\
\hline & {$[\mathrm{P} 10 \mathrm{c}=0]$} &,- 242 & ,196 & $-1,238$ &, 216 &,- 627 & ,143 & ,003 & 1,238 & ,235 \\
\hline & [P10c=1] &,- 208 & ,187 & $-1,110$ & ,268 &,- 575 &, 160 & ,003 & 1,110 & ,198 \\
\hline RAW & Intersección & 1,571 & , 127 & 12,352 & ,000 & 1,321 & 1,821 &, 254 & 12,352 & 1,000 \\
\hline
\end{tabular}


Martín Fernández, Diego y Martín Segura, José Aureliano

La importancia de la reflexión antes del disparo fotográfico. Un análisis estadístico de las preferencias de los usuarios.

III CONGRESO INTERNACIONAL DE INVESTIGACIÓN EN ARTES VISUALES :: ANIAV 2017 :: GLOCAL [codificar, mediar, transformar, vivir] http://dx.doi.org/10.4995/ANIAV.2017.4568

\begin{tabular}{|c|c|c|c|c|c|c|c|c|c|c|}
\hline & P17c &,- 011 & , 010 & $-1,013$ & ,311 &,- 031 & ,010 & ,002 & 1,013 & 173 \\
\hline & {$[P 7 c=0]$} & $-1,12$ & ,230 & $-4,876$ & ,000 & $-1,575$ &,- 670 & ,050 & 4,876 & 998 \\
\hline & {$[P 7 c=1]$} &,- 913 & 138 & $-6,605$ & ,000 & $-1,185$ &,- 641 & ,089 & 6,605 & 1,000 \\
\hline & {$[P 10 c=0]$} & ,071 & ,204 & ,348 & ,728 &,- 330 & ,471 & , 000 & ,348 & ,064 \\
\hline & {$[P 10 c=1]$} &,- 006 & , 195 &,- 031 & ,975 &,- 389 & ,376 & , 000 & ,031 & ,050 \\
\hline \multirow{6}{*}{$\begin{array}{l}\text { Importancia } \\
\text { foto digital }\end{array}$} & Intersección & 2,227 & ,591 & 3,770 & ,000 & 1,066 & 3,389 & 031 & 3,770 & 964 \\
\hline & $\mathrm{P} 17 \mathrm{c}$ & ,028 & , 048 & ,574 & ,566 &,- 067 & 123 & ,001 & ,574 & ,088 \\
\hline & {$[\mathrm{P} 7 \mathrm{c}=0]$} & 5,007 & 1,070 & 4,680 &, 000 & 2,904 & 7,109 & ,047 & 4,680 & 997 \\
\hline & {$[P 7 c=1]$} & 5,591 & ,642 & 8,707 & ,000 & 4,329 & 6,853 & 145 & 8,707 & 1,000 \\
\hline & {$[P 10 c=0]$} & 1,049 & 947 & 1,109 & ,268 &,- 811 & 2,910 & ,003 & 1,109 & 198 \\
\hline & {$[P 10 c=1]$} & 1,163 & ,904 & 1,286 & 199 &,- 614 & 2,939 & ,004 & 1,286 & ,250 \\
\hline
\end{tabular}

Entrando en el detalle por variables dependientes, destacas que:

La primera variable dependiente era el primer Factor sobre importancia de los elementos de la fase previa a la toma fotográfica, ejerce una influencia estadísticamente significativa y positiva la variable años dedicado a la fotografía, con un coeficiente positivo de 0.024. Lo que indica que a mayor experiencia, más importancia se concede a los elementos definidos de la fase previa a la toma fotográfica. También muestra una importancia significativa, aunque con un p-valor algo más alto (aceptable al tratarse de variables cualitativas), el hecho de "no dar por finalizada su formación relacionada con fotografía". Esto corrobora un aprecio por el control adecuado de los aspectos que abarcan la fase previa a la toma fotográfica.

La segunda variable dependiente era el segundo Factor sobre la importancia de los elementos de la fase previa a la toma fotográfica, la influencia estadística más clara la ejerce el "no dar por finalizada su formación relacionada con fotografía", junto a los años dedicado a la fotografía. Aunque con p-valores del 0,17 en el primer caso y del 0,30 en el segundo. Sin embargo, los estudios relacionados con la fotografía ejercen una influencia negativa en este caso. Este resultado ratifica una idea de algunos expertos: la ventaja técnica con la que contaban los fotógrafos que trabajaron en el proceso fotoquímico ha sido superada por la tecnología digital (Fontcuberta: 2003). Por tanto, los fotógrafos que se comienzan a demandar son aquellos que, teniendo un profundo conocimiento de los procesos de trabajo fotográficos, también están formados en los conceptos, las ideas y el deseo de contar.

La tercera variable dependiente era el denominado tercer Factor, que resume los tres elementos considerados más importantes sobre la importancia de los elementos de la fase posterior a la toma fotográfica, la estimación indica que las variables de experiencia, formación y estudios ejercen una influencia clara estadísticamente significativa y positiva en el mismo, con p-valores bastante bajos. No obstante, en el caso de los estudios relacionados con la fotografía, también se observa una influencia significativa en el caso de no tenerlos.

La cuarta variable dependiente fue la de uso del programa de edición de imágenes Lightroom, que resultó estar influenciada por los años de experiencia posiblemente porque cuanta más experiencia se tiene, más importancia se otorga al programa informático, probablemente por la similitud entre el flujo de trabajo y las herramientas con el procesamiento tradicional de fotografías en laboratorio. En el caso de los factores de formación y estudios, influyen de forma negativa ya que cuanta más formación o estudios se tiene, menos importancia se presta al programa informático. Se puede interpretar como un síntoma del valor por la previsualización y la importancia del trabajo anterior al disparo.

La quinta variable dependiente, sobre el uso del programa de edición de imágenes Camera RAW, resultó estar influida por los años de experiencia y el tener o no estudios relacionados con fotografía, aunque de una forma negativa. Mientras que el factor de formación no ejerce influencia estadística importante, con lo cual, el programa clave en este estudio es Adobe Lightroom.

Por último, la sexta variable dependiente, sobre la importancia de la edición previa y posterior en el sistema digital, está influenciada por el hecho de tener o no estudios y por la formación no terminada. Aunque no por los años de experiencia, por lo que se hace referencia a lo dicho en los resultados obtenidos. 


\section{CONCLUSIONES}

Como se mencionó al inicio del trabajo, se sabe que el sistema digital permite al aficionado fotografiar de manera mecánica, pero se pretendía conocer si se ha extendido entre los profesionales y futuros fotógrafos una cierta despreocupación sobre la expresión fotográfica y su intención más allá del disparo, además de una forma de trabajar que obvia la toma de decisiones previas antes del disparo.

De modo que se reflexionara si actualmente resulta necesario posicionar de nuevo a la fotografía en un sistema de trabajo controlado e intencionado, dirigido hacia el 'buen hacer fotográfico', para determinar si las funciones del fotógrafo siguen siendo las mismas que en el sistema anterior.

Los datos recogidos en este análisis corroboran que el nuevo sistema ha provocado una confianza en la fase anterior al disparo, pero no tanto una desidia porque los fotógrafos siguen siendo conscientes de la importancia de dos aspectos: experiencia y formación. Es decir, saben que la experiencia aumenta el control técnico. Este posicionamiento reafirma que el fotógrafo es más consciente de su capacidad técnica, de percepción, intuición y sensibilidad.

Al trasladar esta idea al uso del sistema digital, se concluye que el control previo a la toma ahorra tiempo de postproducción y que trabajar así significa valorar que cuanta más información se tenga desde el principio, mayor será la calidad.

Los fotógrafos siguen valorando esta relación, por lo que se puede afirmar que sigue importando de manera positiva el control de aspectos de la fase previa al proceso, especialmente entre los que han trabajado en el proceso fotoquímico.

Por tanto, se trata de fortalecer las ideas previas a la toma y las estructuras de trabajo más allá de la tecnología, reflexionar más y confiar menos en la postproducción, disparar menos y ser más consciente para controlar la situación. Basta con concienciar a los fotógrafos de que es necesario reposicionar la acción de fotografiar en el lugar que le corresponde: en el proceso, para que la postproducción vuelva a tener el suyo, como herramienta.

Así, la calidad técnica -en técnicas de postproducción, sobre el aparato, etcétera.- volverá a estar al servicio del discurso que se quiere construir sin que interfiera en la lectura de la imagen. No hay lugar para una foto idónea sin concepto previo e intención, del mismo modo que el virtuosismo técnico no debe llamar más la atención que la propia imagen (Shore: 2009).

La calidad en este caso no significa que la imagen esté completamente enfocada, nítida, con una escala de tonalidades completa o que siempre haya que disparar en -raw. Se pueden fotografiar imágenes movidas, técnicamente adecuadas al discurso. Del mismo modo que hay trabajos que se pueden disparar en menor resolución para prensa diaria o un portal web.

\section{FUENTES REFERENCIALES.}

Castelo, L. (2006). Del arte al ruido. Una interpretación de los usos no normativos del lenguaje fotográfico. Colección Imagen, Arte y Color. Número 5. Madrid: H. Blume.

Daniel, U. (2005). Compendio de historia cultural. Teoría, prácticas, palabras clave. Madrid, Alianza Editorial.

Flusser, V. (1990). Hacia una filosofía de la fotografía. México D.F.: Editorial Trillas.

Fontcuberta, J. (Coord.) (2003). Estética Fotográfica. Barcelona: Editorial Gustavo Gili.

Laguillo, M. (1995). ¿'Por qué fotografiar? Escritos de circunstancias 1982- 1994. Colección Palabras de arte. Número 1, Murcia: Mestizo.

Pérez L. C. (2009). Técnicas de muestreo estadístico. Madrid: Garceta.

Petruck, P.R. (ed.) (1979). The Camera Viewed: writings on Twentieth-Century Photography. Photography before World War II. Volume 1. Nueva York: Dutton Paperback E.P. Dutton. 
Martín Fernández, Diego y Martín Segura, José Aureliano

La importancia de la reflexión antes del disparo fotográfico. Un análisis estadístico de las preferencias de los usuarios.

III CONGRESO INTERNACIONAL DE INVESTIGACIÓN EN ARTES VISUALES :: ANIAV 2017 :: GLOCAL [codificar, mediar, transformar, vivir] http://dx.doi.org/10.4995/ANIAV.2017.4568

Santos P., J. et al. (1999). Diseño y tratamiento estadístico de encuestas para estudios de mercado. Madrid: Editorial Centro de Estudios Ramón Areces, S.A..

Shore, S. (2009). Lección de fotografía. La naturaleza de las fotografías. Barcelona: Phaidon.

Vauclare, C. y R. Debeauvais (2014). Le métier de photographe. Francia: Ministère de la Culture et de la Francophonie. Recuperado de: http://www.culturecommunication.gouv.fr/Politiques-ministerielles/Etudes-et-statistiques/Publications/Collections-desynthese/Culture-etudes-2007-2015/Le-metier-de-photographe-CE-2015-3 . 